used, the latter instrument dividing the parts without effort, as the osseous texture had become very soft. The head of the femur was found cornpletely decayed, carious, and disorganized, evidently not admitting of any reparative action; it was exactly as if necrosed, for the suppuration had penetrated the cancelli of the bone. No ressels required any ligature, and Nr. Stanley expressed his opimion that, by the above-described excision, the life of the patient, which must evilently soon have given way, was very likely to be saved. The parts were neatly brought in ajposition, and for some time after the operation the lithe patient was desired to lie on his chest, in vhich position it was found that the limb lay quite straight, being retained in situ by a splint well padded with cotion wool in the vicinity of the lip.

The boy his, previous to the operation, been given good diet, cod-liver oil, tonics, \&c.; these were continued after the excision, and the patient progresed very favourably for the first few weels, the wound grinulating very energetically, and the reneral health improving visibly. It is interesting to notice how different, and how very far from exhausting, is the uinlent discharge from a clean wound, unimritated by carious Wone, as compared with the matter profusely poured out from sinuses and fistulæ kept up by disorganizing osseous tissue. After a few months of careful treatment, good riet, and appropriate medicine, the patient was able to get up and go about the ward on crutches; the old fistulous apertures heiled up, and no open wound was left but the remains of the incisions made for the removal of the head of the bone. The progress after the first six months was, however, very slow, and a small portion of the wound was extremely tedious in healing, although some amount of motion was regained in the hiv. The boy was, at the same time, gaining flesh, and after he had remained just twelve months in the hospital, Nir. Stanley thought, in the summer of 1853 , that the change to the sea-side would contribute to the child's nnal recovery. The latter was therefore sent to Margate just one year after the operation, suce discharge remaining about the unclosed wound of the hin.

'The patient's general health gained remarkably by the re moval from the hospital to the bracing air of the coast. He remained at Margate for the summer months, then returned to his parents; and we learn by the last accounts of him that he has grown strong, but that the parts about the hip are not as yet completely cicatrized. It will be clearly seen by this case that no final and satisfactory results should be expected after the resection of some of the larger joints, before at least one year or eighteen months.

From this interesting case we pass to one of a similar nature treated by Mr. Erichsen, at University College Hospital; but before doing so, we should state, as we are on the subject of conservative snrgery, that Mr. Paget has just removed, at this hospital (St. Bartholomew's), the greater part of the os calcis of $a$ patient wbo is now doing well, and that Mr. Lloyd has, in Pitcairn ward, under his care a man affected with disease of the elbow-joint, upon whom he purposes to excise the articulation. The details of the following case were noted by Mr. Godfrey, one of Mr. Erichsen's dressers.

\section{UNIVERSITY COLLEGE HOSPITAL} Excision of the Head of the Femur.

(Under the care of Mr. EnIcissen.)

GEORGE B-, aged fourteen years, was admitted Oct. 31st, 180. The patient is of light hair and complexion, has always enjoyed good general health, and has not been subject to any want. Fight rears and a half before admission, he was pushed lown a flight of steps; this accident gave him but little uneasiness, and he experienced only a slight pain behind the hip-juint. Six months after his fall, he began, however, to walk lame, he felt some pain in the hip, and he would often trip whilst proceeding along. The patient had, soon afterwards, advice at Middlesex Hospital, as out-door patient, when blisters were applied. He experienced no benefit, and placcl himself under the care of Mr. Liston, at this hospital, where he stayed six weeks. Splints were used, and one month after the beginning of the treatment, an abseess formed over the hip-joins, which burst after pontticing, and then closed.

Since that period the boy has been lame, and walked with a cruteil, thongh experiencing no pain about the hij, until two months befure his preant aluission, when an abscess formed and orote. After this. the patient became gradually weaker, with a failure of appetite, and a short time before admission he began to sweat at night.
Erramination on armission. - The boy lies chiefly on his left side, with his right leg advanced in front of the other, making an angle of thirty degrees with the abdomen; the affected limb is about three inches shorter than its fellow. The right matis is more than twice the width of the left, no distinct coxo-gluteal fold being observalle. None of the bony prominenccs are visible, and the pain of which the boy comjulains, when the joint is tonched, jrevents a sufficiently accurate examination from veing made to ascextain their true position. There is considerable apparent motion of the joint when the pelvis in left unfixed, but when the latter is stontly held the motions of the articulation are found very limited. On the onter portion of the thigh, milway towards the knee-joint, there are sereral openinss, evidently the termination of fistulous tracts; the former discharge large quantities of pretty healthy pus. A probe passes obliquely upwards, under the integuments, towards the heid of the femur, but without impinging on any denuded bone. Some of the sinnses pass towarks the frout of the joint, but the rreater number to the outer side. The boy, according to his own statement, is much weaker than he was a short time before he came to this institution, the appetite is bad, and he perspires profusely at night. Pulse active, but small; slight cough for the last week only; no pain in the chest; percussion and auscultation elicit no disease in the lungs.

The boy was ordered good diet, and the following medicines: syrup of iodide of iron, one drachm; iodide of potassium, two grains; infusion of quassia, one ounce; to be taken three times a day; also two drachms of cod-liver oil, twice a clay. Topically, a linseed-meal poultice was applied to the ulcerated portion of the thigh.

The patient progressed extremely well for the first week, at the end of which Mr. Erichsen made a thorough examination of the limb, as the boy was now in a quieter state. It was found that the femur was dislocated on the dorsum of the clium, and that excision of the bone would frobauly be bene. ficial. Mr. Erichsen, however, judged that it would be wise to wait until the patient's health were still more improved.

About ten days after this exumination. Mir. Ericlisen passed a long probe through the highest and largest termination of the fistulous tracts, whilst the boy was under the influence of chloroform. The instrument went to the outer sirle of the prominence supposed to be formed by the trochanter; a narrow bistoury was then glided down to it through the integuments and soft parts, directly ovex the extremity of the protuberance The probe was then passed into the new opening, through which no jus escaped; it came in contact with a hard surface resembling bone, and covered with iense tissue and plastic mafter, but no exposed bone could be felt.

A little feverishness followed this examination, but the unpleasant symutoms were removed by appropriate remedies, and on the $23 \mathrm{rd}$ of Norember Mr. Erichsen proceeded to oyerate.

The boy was narcotized by chloroform, and the affected thigh being carried over the opposite limb, Mr. Erichsen made a -shaped incision over the outer part of the trochanteric prominence, and the bone was laid bare by a little dissection. The head of the femur was then turned ont of its bed by carrying the limb still more across the abdomen, and using it as a lever. When the exposed bony process had been well fieed from soft parts, a section of it was made with a saw. The piece of bone being removed, a carity containing pus and serelal pieces of detached bone, was observed in the neighbourhood of the acetabulum, which latter cavity was partly filled up with plastic matter, but presented a small, slightly rough substance at one point. The latter was scraped with the gonge, and a few bleeding vessels having been tied, a piece of wet lint was placed carefully at the bottom of the wound to arrest the rather free oozing; the whole solution of continuity was then covered with thick large water-dressing, a pillow placed under the leg, and the boy removed to bed. The limb was soon afterwards fixed to the long splint, with two iron brackets substituted for the rood, in the situation of the wound

The inflammatory fever run somewhat high, and the boy complained of much pain for the first few days. The discharge was at the outset thin, but soon became laudable, though now and then a little foetid, and cod-liver oil with occasional anodynes were now given at night.

The patient, one week after the operation, was attacked with serere rain in the elbows, which shifted afterwards to the knee, ankle, and toe on the right side. The progress was, however, furouale; but on the nintl day the right knee was extremely painfil, and on examination found much swollen. This, however, went off in a few days, and on the nineteenth 
day the patient was found grodually improving in health; he had certainly gained Hesh since the operation, was free from pain, and moved easily in ved. The wounds made for the removal of the head of the bone were almost healed, and the discharge came principally from a sinus in its vicinity.

At the present time, about two months after the operation, the boy is still in the hospital; the wounds made by the knife are healed, but the sinuses keep discharging a small quantity of pus. Here, as in the case treated by Mlr. Stanley, it may be said that the patient's life was at a very low ebb, and that the operation has been instrumental in saving him from his impending fate.

In attending Mr. Shaw in the surgical wards of Middlesex Hospital a few days ago, we noticed a patient whose case strongly reminded us of the preceding. In this instance there had been disease of the hip-joint when the patient was four years old, (he is now about eighteen years of age;) dislocation on the dorsum ilii had taken place as usual, the parts had reassumed a healthy action, and for iourteen years the boy had enjoyed free use of the limb, walking, however, lame from the shortening of his right leg. A short time before his admission into the Middlesex Hospital, the joint was all at once attacked with inflammation, without any assignable cause, and pointing is going on in the gluteal region. This shows plainly how liable are those joints which have once suffered to a recurrence of inflammatory attacks. We shall watch this case with much interest, and now leave the hip to take up the subject of excision of the wrist-joint.

\section{Ercision of the Wrist-joint.}

(Under the care of Mr. EnIcriser.)

This is an operation which, as far as we can judge, is not likely to become a favonrite: first, because the results are not very encouraging (as we stated above); and, secondly, on account of the little use which a patient could make of an anchylosed hand. If it can eventually be shown that a certain amount of articular motion may be regained, and that both the flexors and extensors can, after excision of the joint, again act upon the palm and fingers, there will be an inducement for surgeons to adopt the operation. We confess ourselves partial to conservative surgery; the principle is extremely just, and does honour to the modern schnol, bat we may perhaps express some doubts as to the advisability of carrying out the principle respecting the wrist-joint. This operation will, however, be best judged by its results; and though but very few cases have occurred, they will aicl the inquiring surgeon in forming an estimate of an operative procedure upon which we would not be understood to cast any discredit. The following case was reported by Mrr. Ramsbotham, a dresser in Mr. Erichsen's wards.

Ann M- , aged twenty-eight years, was admitted Oct. 17th, 1853. There is no hereditary tendency to be traced; the patient's father died of pulmonary disease, and the nother of dropsy; her brother is also troubled with dyspnoea. The woman herself has suffered from shortness of breath in cold weather ever since she can rememler. She never expectorated blood, but, though living in the conntry, has fared very badiy. About three years before admission, she strained her wrist in wringing clothes, the part remained rather painful at times, and was weak for two years. Within the last twelvemonth the joint became swollen, and the pain permanent, though no new injury had been inflicted. Two months before admission, two distinctly limited swellings appeared on the dorsal ispect of the wrist-joint; the abscesses soon broke, ind have been discharging ever since, the pain having materially increased.

State on $A$ drizission. - The dorsal aspect of the right wrist is much swollen, and of a dark-rerl colour; the tumefaction begins from about an inch above the styluid process of the radius, and extends down the hand. On a level with the styloid yrocess is a pouting fistulous opening, about half an inch in diameter, throngh which the probe can be passed into the joint in various directions, meeting with many points of diseased bone. Just below, and to the outer side of this aperture, another opening is observed, through which the probe can be passed straight into the joint, so that the extremity of the instrument may be felt on the palmar aspect of the articulation. Diseased bone, towards the end of the radius and ulna, can be felt, and the greater part of the first row of carpal bones seem in the same condition. On a level with the styloid processes the circumference of the joint is eight inches, and on the sound side five inches. No flexion or extension can be performed by the patient, but she slightly pronates and supinates; there is more pain by night thin by day, though $i v$ is iot of a grating cliaracter. Foll diet, milk, and beef-tea were ortered.

On October 19 th Mr. Erichsen remotek a mamber of irregular fragments of carious bone, constituting the whole of the first row of the carpus, together with about an inch of the lower end of the radius, and a little more than the styloid process of the ulna. This was effected by making a transverse incision over the centre of the dorsal aspect of the joint, and two other incisions at right angles to this, reaching from an inch above the styloid process; a flap being then raised over the surface of the extensor tendons, from between which were removed the fragments of bone. Mr. Erichsen succeeded in doing this without injuring any of the extensor tendons, with the exception of one small one, (probably the extensor minimi digiti. Considerable hxmorrhage occurred at the time, but no vessel required ligature; a pad of lint was applied as a compress, and the arm placed in a splint, reaching from the elbow to the fingers'-end. From about sixteen to twenty ounces of chiefly venous blood were lost during the operation. Water-dressing was subsequently applied, and the patient given an opiate to allay pain

On Oct. 31 st, twelve days after the operation, the patient's health was considerably improved; she felt stronger, and the appetite was good. The wound was granulating healthily, and the discharge very laudable. Gentle pressure was applied by means of pressure and bandaging.

On the twenty-second day after the operation Mr. Erichsen ordered methodical strapping to the limb, a little above and below the granulating surface, which latter looked very healthy. Whenever the granulations appeared exuberant, they were restrained with sulphate of copper. The plaster had, however, soon to be removed to give free exit to the matter, and the many-tailed bandages were substituted.

The wound went on healing satisfactorily; but on the thirtythird day potassi fusa was used in two places to give exit to any retained matter. On the forty-fifth day the patient was found to be suffering from bronchitis, the wound was healing, and the discharge moderate; she wished to be made an outpatient, and left accordingly.

Nothing positive as to ultimate results can here be stated; time will show whether the patient will recover partial use of the hand. Let us, in the meanwhile, consider the cases of excision of the wrist-joint at King's College Flospital.

ON THE

\section{PATHOLOGY AND TREATMENT OF UTERINE} CATARRH AND INTERNAL METRITIS.

\section{Br E. J. TILT, M.D.,}

SENIOR PHYSTCIAY TO THE FARRINGDON GENERAL DISPEYSARY AND IYINGTN CHARITY, AND TO THE PADDIXGTON TREE DISPEXSAIR FOR WOMEN AND CHIDUEN.

(Concluded fiom p. 623, rol, ii. 1853.)

HAVING sketched the pathology of intermal metritis, as far as it is now possible to deduce it from the recorded experience of others and myself, I shall now disenss the treatment of thedisease, which is beset with difficulties, and often unavoidably protracted to a great length of time.

There are certain general indications of treatment available in all cases, whether the uterine mucous membrane does or does not present organic products on its surfuce. Thus it is necessary to ascertain by a careful examination, whether the hæmorrhage does not depend upon some erectile development at the orifice of the neck of the womb, as in cases alluded to in the previous papers. The menorrhagia must be restrained by the means usually recommended, among which we may mention the horizontal position in a cool temperature; the application of cloths steeped in cold vinegar and water to the pubis and the inner part of the thighs; the injections of cold water or cold alluminated water, to the ragina and rectum, two or three times in the course of the day. Such measures, however, will seldom succeed unless they be associated with the internal exhibition of ergot of rye in doses of from five to ten grains three or four times a day, from which we think the most benefit is to be derived, though in some cases the practitioner will be obliged to ring the changes on mineral acids, acetate of lead, tannin, gallic acid, \&ce, according to the rules laid down in works on therapentics, to which I refer the reader.

The patient's strength wist be kept up by such an amount of food as can be digested; but it should be taken cold. Wine and stimnlants should be aroided, and all drinks should be as 